\title{
Ouverture de 'Market-Driven Management'
}

\author{
Jean-Jacques Lambin ${ }^{* *}$, Silvio M. Brondoni ${ }^{* * *}$
}

\begin{abstract}
Over-supplied global markets (i.e. with open competition and with production exceeding the absorption capacity of the demand) show clearly the primacy of product intangible assets (i.e. pre/post sales services, logistics, merchandising, design, packaging, etc.) which in turn help to enhance the corporate intangible assets (corporate culture, information system and brand equity).

In over-supply, market-driven orientation configures a policy of long-term corporate development, where the competitive constraints of cost compare themselves with the primary goal of meeting demand.

The over-supply outlines new logics of competition, with a profound rethinking of the theories of management and marketing.

In today's international dominance of over-supply, the strategies of 'hypercompetition' are based on the assumption that a business is highly profitable only for firms that shape innovation and create 'demand bubbles'.
\end{abstract}

Keywords: Market-Driven Management; Over-Supply; Competition; Global Corporations; Global Markets

\section{Overture}

Large international firms operate in contexts dominated by the globalization of markets, which enhance the achievement of viable economies of costs (procurement, manufacturing, distribution, communication, sales).

The enormous economic and financial benefits achieved by the pursuit of increasing economies of scale (supply-driven management), however, sometimes leads firms to neglect even the demand satisfaction; this conduct, however, tends to reduce the competitive strength of organizations working over large geographical areas because of: excess of decision-making centralization, a progressive insensitivity to local markets, a partial implementation of global strategies at the local level, the weakening of brand image and the impairment of brand equity.

\footnotetext{
${ }^{*}$ The Authors: S.M. Brondoni § 1; J.J. Lambin § 2;

${ }^{* *}$ Full Professor of Management, University of Milan-Bicocca (jean-jacques.lambin@ unimib.it)

${ }^{* * *}$ Editor-in-Chief Symphonya. Emerging Issues in Management (silvio.brondoni@unimib.it)
} 
In fact, the current over-supplied global markets (i.e. with open competition and with production exceeding the absorption capacity of the demand) show clearly the primacy of product intangible assets (i.e. pre/post sales services, logistics, merchandising, design, packaging, etc.) which in turn help to enhance the corporate intangible assets (corporate culture, information system and brand equity).

In over-supplied markets (where products are becoming more sophisticated, but quickly made obsolete by easy imitation) we can observe a product and corporate intangible economy that on one hand emphasizes the role of multimarket and multi-business firms, and on the other hand reduces the competitive significance of the sector: thus, the traditional analysis based on maturity/novelty industry give way to competitive-intensive business activities, for which the creation of new value presupposes the destruction of earlier values. Phenomenon whose consequences are obvious both in the 'up \& down' share prices both in the processes of improvement of the degree of 'harmony' with the staff, both in product innovation aimed at processes of customer fidelization. In this sense, for example, a 'historical' brand of beer that introduces a new, 'revolutionary' plastic packaging (rejected by old consumers, but that opens up new customer segments) sets the conditions for creating a new value for the 'firm and at the same time determines the profound modification of existing corporate values of marketing, finance and human resources.

In over-supply, market-driven orientation configures a policy of long-term corporate development, where the competitive constraints of cost compare themselves with the primary goal of meeting demand.

The over-supply becomes a structural factor for the development of enterprises, which are confronted with an increasing glut of goods (produced at decreasing costs for the continuous technological development); goods must also be offered with an abundant alternatives variety to meet the needs of increasingly sophisticated consumer and motivate a demand with an increasingly unfaithful behavior.

Over-supplied markets outlines new logics of competition, with a profound rethinking of the theories of management and marketing. The latter, on the other hand, have been developed in very different conditions of demand and supply. The basic principles of 'rational management' were in fact designed to 'drive' a demand which was much higher than the production possibilities of the offer (phase of scarcity economy, which has characterized the U.S. until the 40s and Italy until the late '50s); later, the development of international markets has introduced new paradigms of business management, directing it to stimulate the request for news from the demand side, which actually put it in continuous dynamic balance with the offer (phase of welfare economy, which persisted on international markets until the late '80s).

In today's international dominance of over-supply, the strategies of 'hypercompetition' are based on the assumption that a business is highly profitable only for firms that shape innovation and create 'demand bubbles', rapidly coming to meet them ('time to market') and abandoning them at the right time ('time competition'), leaving its competitors-imitators the residual portion of the bubble (generally dispersive and not very profitable for the crowding of alternative proposals). 
Strategies of hyper-competition that break the rules of static oligopolistic 'one-toone' comparison and propose a model for systemic competition, based on the absolute centrality of the 'cultural uniqueness' of the firm, to develop with a 'market-driven management' philosophy (as is evident from the most recent policies of 'mergers and acquisitions' and 'brand portfolio re-engineering' undertaken by large corporations).

A concrete example, which also brings the experience of Symphonya-Emerging Issues in Management, is configured in publishing industry (books, newspapers \& magazines, scientific research reports, art editions, comic books, music cassettes and CDs, films, documentaries, 'multimedial education', etc.), where the new competitive conduct, derived from e-commerce and globalization, specifically concern: the structure of production costs, timing and modes of dissemination of the works, and first of all, the structure of the design-sale cycle.

In traditional markets (i.e., in non-saturated markets with low imitation and where communication follows production and sale), competitive behavior are summarized in the logic of 'First Business, Second Community' in practice 'before you produce and then you sell'. So, for example, a book is first conceived, written and printed (with many constraints, such as: size of the print run; range of offered translations; variety of issues prepared; etc.). It is then distributed, with many other constraints imposed by: coverage of points of sale, shelves quality; not availability; etc.). Finally, potential buyers can buy it, ignore it, or even 'pirate it'.

In over-supplied markets, however, the rules of competition have been revolutionized, since the markets are saturated, companies operate in conditions of 'time-based competition' and communication addresses sales and production. In this context, the logic of competition becomes 'First Community, Second Business' or 'before you sell and then you manufacture'. A new competitive approach, therefore, with a reversal of the hierarchy between 'customer satisfaction' and production: goods are realized only when the level and intensity of satisfaction expressed by specific groups (communities) of buyers are known.

The example above shows an new sale-production cycle, which is typical of epublishing. A book is therefore presented in 'web windows' but printed only after a customer has purchased it, thereby eliminating the problems of unsold copies, made and stored in the 'pipeline'. Furthermore, the volume is 'tailored' achievable (with a flexibility and variety never seen before, in terms of: edition, size, colors, translations, etc.). The volume is then made available immediately, according to the rules of the virtual stock (overcoming the constraint of titles in reprint or out), with easy access to the network and can be produced wherever you want, also in a single copy.

\section{Emerging Issues}

The choice of market orientation as a philosophy of management puts in place a system that (a) gives the word to consumers-customers-citizens; (b) directs the investment and production as a function of individual and collective needs (expressed or not) and; (c) respects pluralism and diversity of needs through market segmentation, and by adapting to individual situations; (d) encourages innovation and entrepreneurial activities; (e) becomes careful to the social and 
cultural impact of its economic action; (f) and contributes to find solutions to the needs of the population.

In what is today called the new economy, are observed in parallel with the globalization of markets, the following changes: the adoption of new behaviors by urban consumers, the arrival of new actors on the markets, the emergence of new counter-powers, the development of new communication technologies and, above all, the emergence of new values that expand the traditional notion of economic performance, giving it a social dimension.

\subsection{The New Consumer Citizen}

The economic prosperity of the last thirty years, the elevation of education and consumerist culture helped to make consumers more experienced and more professional in their buying behavior. No longer mild and easily manipulated, buyers are now an organized and structured force that change the nature of relations between the firm and the consumer. Three features characterize the new consumer.

- A feeling of power. Consumers evolve in markets where supply is abundant, where competition is very strong and there are a multiplicity of sources of information. Furthermore, the very strong influence of consumer organizations and numerous non-governmental organizations (NGOs) represent a significant power, opposed to the firm's power.

- A great professionalism. Educated and experienced consumers behave as consumers increasingly savvy, informed and able to make choices between brands and store brands - regardless of advertising suggestions. 'Consumer-protagonists', they always more want to show their own point of veiw and do not hesitate to contact the firm today, as evidenced by the growing success of consumer-services.

- New expectations. Once met the basic needs, consumers seek higher levels of satisfaction, require products to suit their specific needs, and are geared toward new values, such as the enhancement of the time, the sake of change or the need for stimulation and pleasure. Consumers' choices are opportunistic: now the luxury, now cheap products, depending on the situation of consumption. Additionally, consumers want a consumption ethic and don't want to be faulted for their purchases or even by advertising associated with a brand. He wants to be heard, listened, understood, considered and will give any cause for dissatisfaction to the manufacturer.

The growth of consumer power generate from the latter claims that contribute directly to improve the functioning of the market: freedom of choice, information, pricing pressures, product safety, fairness in commercial transactions. The relationships between consumers and manufacturers is changing in favor of a new sense of responsibility in the face of changing populations and their wellbeing.

\subsection{Access of 'Poor' Countries to the World Market}

The power of consumers is a phenomenon just in rich countries and is far from having the same amplitude in the developing countries, although the consumerist movement progresses rapidly in the countries of Central and Eastern Europe (Bourgoignie and others, 1998), as in Latin America. There is thus a form of 
inequality between rich and poor countries, that only education and access to information will reduce. Globalization can thus play an important role in this regard because of the interdependence of the markets they help create, and the development of electronic communications that allow the exchange of information anywhere, anytime, from anyone.

\subsection{The Globalization of the World Economy}

The late nineties and the beginning of this millennium are characterized by the completion of the process of internationalization of the world economy, through the process that is called globalization.

Today in a growing number of sectors, the relevant geographic market is no longer the state or continent, but all the industrialized countries. The competition has become global.

This development, particularly profound in Europe, given the size of national markets, renders obsolete the traditional multinational organizations (or multidomestic) which must therefore be replaced by trans-national forms of organization. The implications of globalization are many.

Firstly, there is an increasing economic interdependence, which means that the domestic markets can no longer be seen as separate, but should be considered as part of the same target market. In other words, what happens in one market affect other markets. Thus, the crisis in South-East Asia had a direct impact on the economy of Brazil.

\subsection{The Development of Transnational Segments}

Globalization determines supra-national segments, i.e. groups of consumers in each country and with the same behaviors or expectations.

Globalization thus implies the non-uniformity (or standardization) of lifestyles between different countries, but simply recognizes that, in each country, there are groups of consumers who have the same needs and can therefore be approached in the same way (i.e. with the same brands, the same advertising, etc.).

Many reasons pushing toward an economic organization more closely to local needs. On one hand, globalization does not imply identical treatment of all markets and on the other hand, the individual achievement requires that the mass-market economy is combined with a renewed attention to the expectations of the individual. The emergence of this combination in the industry or mass level (masscustomization), characterizes today's global competition.

\subsection{The Assertion of Local Identities}

Along with globalization, today we are witnessing a real explosion of identity achievements by Nation-States, religions, ethnic groups or linguistic communities. The fact that a dominant country tent, voluntarily or not, to impose its culture, language and ways of life can give the illusion of uniformity. Beneath the surface layer of uniformity created by some brand (always the same: Disney, Hollywood, McDonald's, Coca-Cola, Marlboro...) lie numerous differences of civilization, 
religions, nations, races and languages. Moreover, in today's world the need to maintain and assert cultural differences is stronger than ever.

The amplitude of the identity crisis is such that you think it will be the principle of subsidiarity to drive the evolution of the world in the coming years; in this sense whenever possible, problems should be solved locally. By contrast, for subjects such as ecology, security, terrorism, health, etc., a form of world government is necessary, given that these are problems that can only be solved at a planet level. If the existence of a future world government would seem likely today, it is however clear that forms of worldwide plan, similar to those that took place in Kyoto and Montreal in the ecological field, can effectively contribute to solve these global problems.

\subsection{The Retailers' Internationalization}

In the markets of mass consumption, the new development of recent years, both in Europe and the United States, is the growing power of distributors' brands, that from passive intermediaries have become entrepreneurs just like producers, developing brand strategies based on own-brands.

The supermarkets have also launched a significant process of internationalization, as demonstrated by: the arrival of the American Wal-Mart in Germany and in Great Britain, the growth of the Delhaize Group in the U.S., increased investment in Asia by the Pinault Printemps Redoute group (PPR) and the Delhaize Group, the merger plans of Kingfisher (UK) and Metro (Germany) which will create the first paneuropean distribution giant.

These developments change the balance of power between manufacturers and retailers. In fact, in the food sector, the market power is unquestionably passed today by the distributors. Powerful brands such as Coca-Cola or Nestlé today need first of all the retailers that on the other hand need the big brands to continue to grow.

It must be noticed that this development creates a form of vertical competition in distribution channels that can only help consumers by lowering the power of powerful international brands, fostering adaptation to local needs and encouraging price competition, as the success of distributors brands. In the consumer market, retailers have become key players actively participating in economic globalization.

\subsection{The Socio-Ecological View of Consumption}

For ten years, ecology has had a right of citizenship in all industrialized countries. The environmental movement reveals the awareness by the market of the limited natural resources, the uncontrolled growth of waste and the social cost of consumption. This realization that comes from the citizens and their purchasing power, change the vision of consumption, which is no longer regarded as a good, but taking into account the implications upstream (opportunity costs) and downstream (prevention costs and/or repair) of this consumption. The environmental movement campaign for the recognition of these neglected social costs by offering a price of use of the environment, which has been regarded until now as a for-free good. 
The eco-balance has recently become the basic tool of ecological consumption and green management. This is to analyze the impact of a product on the environment, throughout his life, from cradle to the grave.

Thus, for example, has become usual to be specified by a potential supplier the way in which the component or the raw material incorporated will be recovered, recycled or destroyed at the end of its useful life. This ecological view of consumption is well illustrated by the new European Directive on Scrapping Vehicles.

In most industrialized countries, have also been used by governments eco-taxes or fees to cover the costs of waste management, which has created new markets for recycled products.

The environmental movement, revealing the emergence of new needs in society, represents a challenge for the firm which must therefore reconsider the design of their own products 'from cradle to the grave', revision that has an impact on the entire value chain of the firm. From this point of view, the ISO-14001 certification will likely become a necessary condition (as is already the norm ISO-9000) to be selected as suppliers in international trade.

Now considered to be irreversible, this vision of socio-ecological consumption is the main progress in the economic reasoning that, by setting a price for use of the environment, says that the prevalence of collective needs over individual needs, thus stopping a form of savage capitalism, insensitive to external effects of their economic action. This cultural phenomenon appears as a new social movement that changes the economic world and the political sphere.

\subsection{The New Role of Nation-State}

The globalization of the economy raises questions about the management of specific national forces and resources, as well as the role of the state. Is well established that Nation-States are destitute of some of their prerogatives, because their authority at trans-national level has weakened. A market economy needs a strong State that establishes and enforces the rules of the competitive game. Is the State, for example, that is maintaining the balance in macro-economic (especially price stability) and ensuring a minimum of social cohesion and solidarity. The market needs the State to function properly.

In the absence of an international court, globalization contributes to weaken the role of Nation-States; the problem that then arises, provided that one can talk about global village, is which city council govern the global village? Perhaps it is more reasonable to believe in the shop or in the global supermarket, rather than in the global village, which would imply a cultural uniformity, social or political unlikely.

There are supranational institutions that work well, as the European Commission (for example, on the protection of privacy), the Competition Commission (for example in the case that pitted Boeing to Airbus), or the OECD (for example, on the fight against corruption), which shall establish guidelines for constraining the Member States.

Similarly, the World Bank, the International Monetary Fund (IMF) and the World Trade Organization (WTO), play an effective role, as illustrated by the resolution to the crisis in Southeast Asia. It would demand that these international 
organizations, the same way as companies integrate into their practice vision socioeconomic economy developed at higher levels. Finally, Nation-States are not helpless ones, as the experience of Chile in the fight to the volatility of capital.

The new capitalism therefore needs powerful counter-powers that go beyond the power of Nation-States. Contrary to the claims of militant anti-globalization, therefore, need to strengthen the power of the WTO, IMF and World Bank to create new institutions to take charge of issues such as environment, nutrition, health, to deal with the risk of sinking into a savage capitalism operating in a completely unregulated market.

\subsection{The Interconnected Global Economy}

The new tools of sales and communication are now changing, driven in particular by the development of Internet and the technological convergence among telecommunications, audiovisual and computer science.

The main aspect is that world economy becomes an interconnected economy in which the actors (suppliers, sellers, buyers, distributors, consumers, etc..) are no longer abstract entities or institutions, but millions of people who express themselves, are included and listened, and in this way are thus encouraged dialogue and relations of the individual one-to-one, together with a process of economic democratization.

The revolution of electronic commerce in particular implies a separation between sale and purchase, as well as between sale and production (Drucker, 2000). In this type of situation, the access market control becomes the main aspect: in fact, instead of selling what they can produce, the virtual company will sell what they can distribute. It follows that the know-how and distribution logistics becomes most important strategic competence.

Electronic commerce has the following other features:

- full information about prices;

- high ease of comparison of bids;

- low barriers to entry;

- weak differentiation potential;

- lack of protection for inventions;

- selection of messages from visitors of a site;

- unfaithful behavior of buyers;

- perception of substantial equality of the incumbent firms.

We are therefore very close to a situation of perfect competition and, in such a context, one may wonder about the profit potential of the virtual enterprise, since the main weapons of strategic and operational marketing (differentiation, loyalty, advertising image, etc.) are practically neutralized.

We must add that electronic communication has also radically changed the relationship with the market, in particular with reference to the following points:

- active communication, bidirectional;

- advertising required and no longer suffered;

- communication and information related to the facts (product, performance, price);

- $\quad$ spreading more selective system of personalized messages; 
- very egalitarian medium, in which the incumbents have the same credibility;

- global communications activated anywhere, anytime and by anyone.

These changes in market organization deeply change the relationships between customers and suppliers, between suppliers and distributors and between businesses and consumers. Such developments strengthen competition, market transparency and the power of initiative among buyers who are increasingly in a position to impose price. Many observers agree that this evolution is able to reduce the gap between rich countries (or regions) and poor countries (Prahalad, 2000), in particular by providing access to global markets at low cost, to anyone with ideas or know-how, and not just a social elite that has amassed a fortune. If the countries of the South have benefited from the investments relatively less than developed countries, we should note that in the new economy are now important primarily the resources of intelligence and ideas (knowledge) that can be mobilized through the Internet. More than the physical capital is now the creative knowledge (Nonaka and Tackeuchi, 1997) to be the key to the new economy.

\subsection{The New Values: Corporate Citizenship}

Corporate social responsibility represents a further evolution that assert itself increasingly in industrialized economies. This realization is based on three findings.

To develop, every business needs a healthy environment and prosperous future: do not build an enduring economic progress on a social disaster. A hostile and degraded environment generates insecurity for the physical safety and risks of social explosion.

The welfare state and the tax burden have clearly shown their limits, both in terms of quality and finance, raising labor costs and weakening competitiveness that, nowadays, must be global.

Instead of paying more taxes, civil society must react and engage in areas where it is responsible.

A citizen organization -small, medium, large or public- is then an organization that, beyond its direct activities, aims to protect social and natural environment and be in solidarity with the communities where it live and exists. By participating in society, the firm commits its expertise in civic actions in order to resolve certain shortcomings of society, together with those involved and a complementary role to public services, local authorities and the associative sector.

This perspective of responsible management is progressing quickly among businesses, as evidenced in particular by the development of social and educational activities triggered by the firms together with the dissemination of ethical papers, where companies define rules regarding their products, the information made available and relationships with both their customers and the society.

Consequently, the strategy of 'well-doing' is perfectly compatible with the objectives of contemporary capitalism. Contrary to what Van Parijs writes (2000, p. 3), the willingness to steer the economy towards a more ethical direction is not self-destructive when is applied to the company itself, since this evolution of business ethics is just a market demand, in this case expressed by consumerscitizens. It is therefore just under the pressure of the market that firms adopts 
ethical behavior. In the new economy, moral behavior becomes a competitive advantage, as demonstrated by the success of ethical investment funds.

An answer to the problem of inequality is the civic vision that firms are the most powerful force for change in the modern world, the force with the most important impact (positive or negative) and that this force can be put at the service of solving social and environmental problems of our age. This does not mean that the institutions traditionally responsible for these matters (State, supranational organizations, schools, unions, etc.) should disinterest of these issues but, more prosaically, that their action, less creative, more bureaucratic and slower, can be reinforced by the firms' skills.

For the company this new view implies the need to undertake the search for a 'triple bottom line', of a performance that combines the three objectives of sustainable development: economic growth, social equity and environment protection (Elkington, 1997).

\section{Bibliography}

Aaron D., How US and EU Backed Net privacy, International Herald Tribune, June 20, 2000.

Alternatives économiques, Les placements éthiques, 1999.

Bougoignie Th., Lacoste A-C., Maniet F. et Pritchard J-P., Towards European Harmonisation: Consumer Law and Institutional Structures in Eleven Central and East European Countries, Université Catholique de Louvain, Centre de droit de la consommation, PHARE/TACIS, 1998.

Brender A., L'impératif de solidarité, Editions La Découverte, Paris, 1996.

Drucker P., Can E-Commerce Deliver?, The World in 2000, The Economist, p. 122, 2000.

Elkington J., Cannibals with Forks, Capstone Publishing, 1997.

Kulwant Sing, Ghesquière F., Reinventing Government: Autonomous Agencies in Singapore, CEMS Business Review, vol. 2, n. 4, 1998, pp. 317-329.

Lambin J.-J., Market-Driven Management, Strategic and Operational Marketing, Macmillan Business, London, 2000, (see Le marketing stratégique: du marketing à l'orientation-marché, Ediscience International, Paris, IV ed., 1998).

Laudicina P.A., The Globalization Ledger, Executive Agenda, vol. 3, n. 1, pp. 61-69, 2000.

Libert B., L'entreprise citoyenne, de quoi s'agit-il?, L'Expansion Management Review, September, 1996.

Means G., Schneider D.M., MetaCapitalism, John Wiley \& Sons, New York, 2000.

Minc Alain, www.capitalisme.fr, Paris, Grasset, 2000.

Porter M., L'avantage concurrentiel des nations, InterEditions, Paris, 1993.

Nonaka I., Takeuchi H., The Knowledge Creating Company, Oxford University Press Inc., Oxford, 1995.

Rachline F., Services publics et économie de marché, Presse de la Fondation nationale des sciences politiques, Paris, 1996.

Utopies, L'entreprise citoyenne, Paris, 2000.

Prahalad C.K., Let's Focus on the Digital Dividend, European Business Forum, n. 2, 2000, pp. 6-7.

Schwartz P., Blair Gibb, When Good Companies Do Bad Things, John Wiley \& Sons, New York, 1999.

Tamzin Booth, Ethics Lesson: Principles Pay, The Wall Street Journal Europe, June 2-3, 2000.

Time Magazine, Europe’s 50 Hottest Tech Firms, Special Report, June 19, 2000.

Utopies NewsService, L'actualité mensuelle de la consommation du 21e siècle, n. 3, Juin 2000.

Van Parijs P., L'éthique à l'épreuve du marché mondial, Louvain-la-Neuve, 2000. 
van Waterschoot J., Taxe Tobin: à l'instar de Robin des Bois, BBL Bulletin Financier, Juillet, $\mathrm{n}$. 2355, 2000, pp. 10-11. 